\title{
QUÍMICA E FILOSOFIA: RUMO A UMA FRUTÍFERA COLABORAÇÃO
}

\author{
Martín Labarca \\ Instituto de Estudios sobre la Ciencia y la Tecnología, CONICET - Universidad Nacional de Quilmes, Roque Sáenz Peña 352 , \\ B1876BXD - Bernal, Buenos Aires, Argentina \\ Nelson Bejarano \\ Departamento de Química Geral e Inorgânica, Instituto de Química da Universidade Federal da Bahia, Campus Ondina, \\ 40170-290 Salvador - BA, Brasil \\ Marcelo Leandro Eichler* \\ Departamento de Química - CFM - Universidade Federal de Santa Catarina, Campus Trindade, CP 476, 88040-900 Florianópolis \\ - SC, Brasil
}

Recebido em 23/7/12; aceito em 20/12/12; publicado na web em 9/8/13

\begin{abstract}
CHEMISTRY AND PHILOSOPHY: TOWARDS A FRUITFUL COLLABORATION. This review seeks to present a brief history of the philosophy of chemistry and the major issues discussed in the framework of this emerging discipline of philosophy of science, such as the question of physicalist reductionism and physical and chemical causality. In this vein, it also addresses the current debate over relevant issues of chemical world such as atomic orbitals, molecular structure, chemical bonding, models and explanations, as well as the foundations of the periodic table. Finally, the importance of the link between the philosophy of chemistry and chemistry education is analyzed, especially in relation to teacher training.
\end{abstract}

Keywords: philosophy of chemistry; reductionism; explanation.

\section{A QUÍMICA E A FILOSOFIA: SÃO MISCÍVEIS?}

Se essa pergunta for formulada em círculos científicos, normalmente, produzirá uma resposta negativa, uma vez que se costuma pensar que a filosofia e a química constituem dois campos de conhecimento separados. Ainda que o significado do termo seja muito amplo, pode-se entender a filosofia como uma disciplina que se ocupa da análise de conceitos. Por exemplo, conceitos que se referem à vida, ao ser, à física, ao conhecimento e à química. Nesse sentido, pode-se questionar sobre o objeto de estudo da química. Apesar de ser uma pergunta, em princípio, simples de responder, quando se aprofundam as definições se observa que as respostas divergem: enquanto alguns autores afirmam que a química é a ciência das substâncias e de suas transformações, ${ }^{1}$ outros indicam que a química é a ciência da matéria e de suas transformações ${ }^{2}$ e também foi assinalado que a química não seria a ciência dos átomos, mas sim das moléculas. ${ }^{3}$ Enfrenta-se, assim, um problema de fundamentação que se refere ao objeto de estudo da disciplina e um atual problema de interpretação (científico-filosófico e não apenas científico): a química se ocupa de substância, de moléculas e de átomos. Mas o que é uma substância, uma molécula e um átomo e como se relacionam entre si?

Apesar da suposição firmemente arraigada segundo a qual a química pode prescindir da filosofia, é possível (e mesmo necessário) construir uma ponte entre ambas as disciplinas. Na realidade toda investigação científica inclui conceitos filosóficos tais como aqueles de lei, verdade, hipótese, tempo, energia, entre outros. E em toda a investigação subjazem certos postulados filosóficos como os de realidade, de cognoscibilidade (ou seja, acerca daquilo que pode ser conhecido) e de legalidade do mundo exterior. Isso pode ser dito de outra forma: existe um mundo exterior independente da existência de um sujeito cognitivo e, em consequência, pode ser conhecido objetivamente, ainda que apenas parcial e gradualmente ou o universo funciona de acordo com as leis naturais. Naturalmente, o químico não se pergunta todos os

*e-mail: exlerbr@yahoo.com.br dias se a realidade existe, tão pouco questiona se os fenômenos podem ser conhecidos ou se existem leis para poder conhecê-los. Ou seja, os cientistas aceitam implicitamente pressupostos filosóficos, na maioria dos casos, sem sabê-lo. Desse modo, então, não apenas a química e a filosofia são miscíveis, como um trabalho conjunto de químicos, historiadores e filósofos da química já produziu importantes resultados para compreender em profundidade a natureza da disciplina e, dessa forma, introduzir enfoques mais amplos tanto no ensino como na pesquisa.

A filosofia da química é, portanto, uma nova subdisciplina da filosofia das ciências, que foi socialmente estabelecida faz pouco mais de uma década. Em 1997, registra-se seu nascimento a partir do número especial dedicado a esse novo campo interdisciplinar pela prestigiada revista de filosofia das ciências Synthese. ${ }^{4}$ Considera-se que a partir desse número especial, a filosofia contemporânea da química obtém visibilidade e é, então, estabelecida socialmente como um campo de investigação autônomo, sendo o de maior crescimento na filosofia das ciências nos últimos quinze anos.

Neste artigo são revistas as causas que impediram sua autonomia como uma área legítima de investigação, bem como são apresentadas as suas principais linhas de pesquisa e de reflexão.

\section{UMA BREVE HISTÓRIA DA FILOSOFIA DA QUÍMICA}

A filosofia das ciências do Século XX, especialmente aquela de tradição anglo-saxã, praticamente ignorou os problemas filosóficos da química. Desde o positivismo lógico até Popper, ${ }^{5}$ Kuhn, ${ }^{6}$ Lakatos ${ }^{7}$ e Feyerabend, ${ }^{8}$ a física foi considerada como a ciência modelo para a filosofia das ciências. Isso é surpreendente devido à extensa e rica história da química como disciplina científica, além de sua relevante posição no contexto atual das ciências naturais. Surpreende também que as complexidades e peculiaridades geradas por milhões de substâncias de diversas classes, que são formadas a partir de pouco mais de cem átomos, tenham sido ignoradas por tantas décadas.

Mesmo que a química tenha gozado de uma ampla popularidade desde meados do Século XIX, somente existem algumas publicações 
isoladas no campo da filosofia da química nas primeiras cinco décadas do século passado. ${ }^{9}$ No período entre 1949 e 1986 um número importante de revistas da Europa oriental publicou trabalhos filosóficos sobre diversos temas do mundo químico. ${ }^{10}$

As causas que impediram o desenvolvimento da filosofia da química são muito variadas. Entre elas, a mecânica quântica teve um papel decisivo na relação entre química e física: o impactante êxito dessa teoria levou a físicos e a filósofos das ciências a aceitar que a química poderia ser completamente reduzida à física. Essa proposição encontra sua melhor expressão na famosa frase de Paul Dirac: "As leis físicas fundamentais necessárias para a teoria matemática de uma grande parte da física e da totalidade da química são completamente conhecidas, a dificuldade é somente que a aplicação dessas leis leva a equações que são muito complicadas de serem resolvidas. Por isso, torna-se desejável que sejam desenvolvidos métodos práticos aproximados de aplicação da mecânica quântica que possam levar a uma explicação das características principais dos sistemas atômicos complexos sem tanta computação". ${ }^{11}$ Se essa afirmação for válida, qualquer problema filosófico da química pode ser explicado no âmbito da filosofia da física. De forma muito próxima a essa proposição, soma-se um realismo ingênuo de corte externalista que, em geral, os químicos e os físicos adotam: somente uma única ontologia constitui o objeto de nosso conhecimento. Ou seja, sobre a base de um enfoque reducionista do mundo químico ao mundo físico, por um lado, e do realismo metafísico, por outro, a química é considerada somente um capítulo da física e os químicos são percebidos como cientistas que fazem “física aplicada". Porém, como afirma Psarros, a própria conclusão que leva a se prescindir da análise filosófica do mundo químico é, em si mesma, uma afirmação filosófica. ${ }^{12}$

Adicionalmente, existem outros fatores que contribuem com o atraso dessa subdisciplina. A percepção de que a química está muito ligada à tecnologia (fabricação de medicamentos, produtos industriais, etc.) somada a uma campanha anticientífica e, especialmente, antiquímica nos meios de comunicação, junto com os problemas ambientais atuais, não favorece a imagem da química na sociedade. ${ }^{13}$ Outro argumento está relacionado à ausência de uma crise nas ciências químicas que marque o curso de sua evolução. Tal crise é muito notável no desenvolvimento da física do Século XIX e no começo do Século XX com a mecânica quântica e a teoria da relatividade. De forma semelhante, as teorias darwinianas modificaram em grande forma o desenvolvimento posterior da biologia, cujo espaço de reflexão filosófica começou na década de 1970.

A negação da filosofia da química como campo legítimo de investigação filosófica sofreu uma forte reação nos anos 1990, particularmente na Alemanha, nos Estados Unidos e no Reino Unido, junto com grupos isolados na Bélgica, na Holanda e na Itália que estavam se constituindo desde finais da década de 1980. Desde essa data, químicos, filósofos e historiadores da química começaram a trabalhar em grupos relativamente formais, mantendo encontros regulares em diversos países. Mesmo assim, a construção de pontes entre a química e as humanidades foi motivada pela indústria química em uma ocasião que a imagem pública da química estava em seu pior momento. ${ }^{14} \mathrm{Em}$ 1994 ocorreu uma série de conferências internacionais, em Londres, Karlsruhe, Marburg e Roma. Em 1997 foi constituída a International Society for the Philosophy of Chemistry que realiza simpósios anuais desde então. Duas revistas especializadas surgiram nesse contexto: Hyle - International Journal for Philosophy of Chemistry (desde 1995) e Foundations of Chemistry (desde 1999). Nos últimos anos, algumas monografias e antologias exemplares foram lançadas por editoras prestigiosas. ${ }^{15}$ Além disso, um ativo fórum de discussão na Internet (Philchem) está contribuindo com a intenção de somar químicos e filósofos a essa nova subdisciplina.

\section{O PROBLEMA DA REDUÇÃO}

O chamado "problema da redução" é o assunto de maior maturidade na filosofia contemporânea da química e, conforme Del Ré, ${ }^{16}$ um dos primeiros filósofos da ciência a discutir a química como uma ciência independente foi Mario Bunge. ${ }^{17} \mathrm{O}$ problema pode ser proposto nos seguintes termos: Qual é a relação existente entre o mundo químico e o mundo físico? A química é uma disciplina científica autônoma ou, ao contrário, é um mero capítulo da física? Existe entre a química e a física uma relação de interdependência? Para abordar essas perguntas, os filósofos da química buscam uma resposta científica, filosófica e historicamente adequada.

O primeiro passo na análise a ser desenvolvida será, então, elucidar os conceitos de "redução". Nesse sentido, é necessário distinguir redução ontológica de redução epistemológica. A ontologia é um capítulo da filosofia (metafísica, em particular) que estuda a realidade, sua estrutura e as entidades que nela existem. A epistemologia é um capítulo da filosofia que, em um sentido amplo, trata do conhecimento em geral ou, em um sentido estrito, estuda o conhecimento científico em particular. Em sua versão tradicional, a redução ontológica implica que as supostas entidades dos níveis não fundamentais da realidade (química, biológica, etc.) não são mais que entidades ou agregados de entidades pertencentes ao nível considerado fundamental (físico). Portanto, o reducionismo ontológico é uma tese metafísica eliminativista, que admite a existência real e objetiva de um único nível de realidade, onde os restantes níveis só possuem uma existência meramente subjetiva ou aparente. A redução epistemológica se refere à dependência lógica entre as teorias científicas: uma teoria pode ser reduzida a outra quando pode ser deduzida daquela. Assim, o reducionismo epistemológico resulta ser uma tese epistemológica segundo a qual a ciência pode (ou deve) ser unificada, deduzindo-se todas as teorias científicas a partir de uma única teoria privilegiada.

Sabe-se que até o começo do Século XX a química seguiu um desenvolvimento histórico independente ao da física: os fenômenos químicos eram concebidos em sua própria especificidade e com suas próprias regularidades. ${ }^{18}$ Entretanto, com o grande êxito preditivo da mecânica quântica, durante o século passado a química fica marcada pelo dictum de Dirac. Ainda na atualidade essa perspectiva continua sendo, em geral, amplamente adotada no seio da comunidade científica. ${ }^{19}$ Então, esse enfoque redutivo atenta contra a autonomia da química como disciplina científica ou, ao menos, coloca a química em uma posição subordinada à física: enquanto a física seria a ciência "fundamental" que representa a realidade tal como é em si mesma, a química resultaria uma disciplina meramente "fenomenológica" que apenas descreve a realidade tal como ela se apresenta. Além disso, o enfoque redutivo atenta contra a legalidade da filosofia da química como subdisciplina da filosofia das ciências: ao ser correto o postulado, as entidades químicas não seriam mais que entidades físicas e, portanto, qualquer problema filosófico da química poderia ser abordado a partir da filosofia da física..$^{20,21}$

\section{O PROBLEMA DO CONCEITO DE ESTRUTURA MOLECULAR}

O conceito de identidade molecular está estreitamente relacionado à noção de estrutura molecular. De fato, em quase todas as descrições químicas se considera que uma molécula conserva sua identidade quando modifica sua forma ou estrutura por meio de vibrações ou rotações, mas a perde ao serem formadas ou rompidas ligações covalentes. A noção de estrutura molecular é a que concentra a maior parte dos debates: é a estrutura molecular redutível ou irredutível? Trata-se de um mero conceito que não possui relação com a realidade? É um aspecto essencial para a identidade molecular? 
A controvérsia acerca do estatuto epistemológico do conceito de estrutura molecular provocou um extenso debate nos últimos anos. A discussão iniciou com o polêmico e desafiante artigo de Woolley, ${ }^{22} \mathrm{em}$ que se indicou que, a partir da teoria quântica, a noção de estrutura molecular se contrapõe à noção clássica e, portanto, não é uma propriedade intrínseca dos sistemas químicos. Na mesma linha, Primas considera que a estrutura molecular é apenas uma poderosa metáfora que não corresponde com a realidade descrita através da mecânica quântica. ${ }^{23}$ Nesse sentido, "a ideia fundamental que as moléculas são construídas aditivamente a partir de átomos, que retêm sua identidade essencial dentro da molécula, é colocada em dúvida". ${ }^{24}$ Apesar disso, Woolley enfatiza que o conceito de estrutura molecular não deve ser abandonado na química, uma vez que ele surgiu em um contexto científico muito diferente do atual. ${ }^{25}$

Não obstante, como corretamente indica Scerri, ${ }^{26}$ a maioria dos químicos reagiria com total incredulidade diante da ideia de que a estrutura molecular é apenas uma "metáfora iluminadora", dado que se trata de um conceito central na química contemporânea. A evidência contundente trazida pela espectroscopia e por outros estudos estruturais - entre eles, as técnicas modernas de microscopia - em favor de sua existência em nível químico, permitiram rejeitar tal perspectiva.

Sobre essa base, Ramsey argumenta em favor de uma interpretação realista do conceito de estrutura molecular. ${ }^{27}$ Ele afirma que, empregando uma descrição física do conceito, observa-se que o mesmo é redutível ontologicamente, ainda que de maneira aproximada. Em consequência, a estrutura molecular é um conceito aproximado com limites definidos. Assinala-se, ademais, que - contra Wooley e Primas - quando esse conceito é adequadamente interpretado, trata-se de um "objeto de crença".

A escala em que o fenômeno ocorre deve ser, também, levada em consideração. Del Ré aprofunda e explicita a questão ontológica associada à noção de escala. ${ }^{28}$ Conforme pondera, um mundo físico consiste de objetos (sistemas físicos) mais ou menos independentes, mas claramente distinguíveis uns dos outros. Ele cita exemplos concretos desses objetos, postos em ordem decrescente de escala: uma nuvem intergaláctica; o planeta Marte; o Oceano Pacífico; o ecossistema da Floresta Negra; uma coruja, o ser humano, o coração de um leão, uma abelha; um ácaro microscópico; uma molécula de DNA; um fóton. Esses objetos pertencem a diferentes campos de investigação e eles são estudados por diferentes disciplinas. Em itálico estão exemplos que pertencem ao nível da realidade de acesso direto para o ser humano. Dessa maneira, a desunião ontológica estaria relacionada às diferentes escalas em que se dão os fenômenos que são estudados cientificamente.

Do ponto de vista da filosofia das ciências, Schummer sugere que pode ser difícil entender do que a química trata. ${ }^{29}$ Em parte, devido aos conceitos unilaterais dos filósofos da ciência que têm sido difundidos desde o início. Eles simplesmente confundiram uma pequena área da física com o todo da ciência ou, para ser mais correto, com a profusão de disciplinas científicas. Ele pondera que compreender o mundo em termos de teorias universais é certamente um objetivo nobre, porém esse não é o único para as ciências e, para a maioria dos campos, isso não é mesmo possível.

Então, em relação à estrutura molecular, sabe-se que a aproximação de Born-Oppenheimer é essencial para relacionar a descrição química e a descrição quântica dos sistemas moleculares. A aproximação de Born-Oppenheimer se fundamenta, para efeito de cálculo, na separação do núcleo e do movimento dos elétrons. Essa aproximação ocorre em duas etapas: em um primeiro passo se ignora o movimento dos núcleos, negligenciando sua energia cinética, e se resolve a equação de Schrödinger apenas para os elétrons; em um segundo momento é reintroduzida a energia cinética dos núcleos. Essa técnica produz resultados aceitáveis com base no pressuposto de que os núcleos se movem lentamente, em relação aos elétrons, por que a massa $M$ do núcleo é muito maior do que a massa $m$ dos elétrons. Porém, um intenso debate de muitos anos envolve a discussão se o conceito de estrutura molecular sobrevive além de tal aproximação. ${ }^{30}$ E ainda que tal aproximação seja uma poderosa e útil ferramenta, não é necessária nem suficiente para formular o conceito de estrutura molecular. ${ }^{31}$

Como se pode perceber, a origem do conflito acerca da interpretação do conceito de estrutura molecular se encontra no surgimento da mecânica quântica na área da química. De fato, desde um ponto de vista quântico a noção de estrutura carece por completo de significado dada a indeterminação da posição e da trajetória dos componentes moleculares. Mas, ao mesmo tempo, o conceito de estrutura molecular ocupa um lugar central nas explicações químicas, inclusive em relação a uma questão tão básica como a identidade das moléculas. Porém, qual é o referente da expressão 'estrutura molecular'? O debate, como se vê, está ainda longe de ser concluído.

\section{O PROBLEMA DO CONCEITO DE ORBITAL ATÔMICO}

O problema do realismo está fortemente relacionado com tal debate, uma vez que se centra na pergunta acerca da existência ou não dos referentes dos termos teóricos na química. Ainda que a controvérsia sobre o lugar do conceito de estrutura molecular tenha propiciado um extenso debate nos últimos tempos, o estatuto ontológico do conceito de orbital atômico dominou a maioria das discussões. Trata-se de entidades existentes no mundo químico, mas não no mundo físico? São entidades "reais"?

Tal como expressa Eric Scerri - um dos fundadores da filosofia da química - essas perguntas indicam um interessante problema filosófico, uma vez que se dirigem ao núcleo do problema do realismo. ${ }^{26}$ Sabe-se que em química molecular um orbital é a região do espaço, próxima ao núcleo atômico, onde existe a maior probabilidade de ser encontrado um elétron. Geralmente, os químicos e os educadores químicos costumam adotar uma postura realista ao atribuir aos orbitais uma existência definida. Mas desde o ponto de vista da mecânica quântica, um orbital é apenas uma ferramenta matemática para expressar tal probabilidade, que é definida mediante uma função matemática (uma função de onda $\psi$ ) que constitui uma solução para a equação de Schrödinger para, por exemplo, sistemas de apenas um elétron, isto é, um orbital atômico para o átomo de $\mathrm{H}$ ou um orbital molecular para $\mathrm{O}_{2}{ }_{2}$. Por esse motivo, os físicos e os químicos computacionais utilizam orbitais como meras ficções matemáticas úteis para o cálculo.

Até o final da última década do Século XX, as discussões em torno do significado do conceito de "orbital atômico" estavam confinadas a aspectos metodológicos e epistemológicos, principalmente no campo da educação química. ${ }^{32,33}$ Porém durante o segundo semestre de 1999 uma notícia correu o mundo da química e da física: pela primeira vez os orbitais haviam sido visualizados e fotografados. ${ }^{34} \mathrm{~A}$ descoberta, que foi capa da revista Nature, foi rapidamente difundida no mundo científico, ${ }^{35}$ foi tratada como um dos cinco destaques do ano na química, ${ }^{36} \mathrm{e}$ cientistas de prestigiosas universidades rapidamente assinalaram a utilidade de tal trabalho como ponto de partida para a compreensão de outros fenômenos do mundo físico. ${ }^{37}$

Apesar do impacto e da expectativa que gerou o resultado da observação dos orbitais, alguns químicos teóricos não-quânticos e filósofos da química questionaram as conclusões propostas pelos investigadores responsáveis pela experiência, assinalando o erro conceitual cometido na interpretação de tais visualizações. ${ }^{38}$ Por exemplo, Scerri insistiu que os orbitais não podem ser visualizados, ${ }^{38}$ não apenas porque as funções de onda não são observáveis, mas porque, desde a perspectiva da mecânica quântica, os orbitais 
são ficções matemáticas desprovidas de qualquer existência real. O autor indica que o erro conceitual consiste em confundir o conceito de orbital com o conceito de densidade de carga (ou de elétrons), o qual se pode observar durante os experimentos. Essa distinção conceitual foi aceita pelos autores do artigo publicado na Nature. ${ }^{39}$

Entretanto, alguns educadores químicos reagiram a tal enfoque normativista sugerindo que a interpretação não realista teria pouco impacto na utilização dos orbitais no ensino da disciplina. ${ }^{40} \mathrm{~A}$ grande utilidade teórica do conceito de orbital na química explica o fato de que, em geral, os químicos e os professores da disciplina sejam realistas em relação a esse conceito, ou seja, que consideram que os orbitais são sim entidades existentes no mundo. Como afirma Roald Hoffmann: "Creio que os orbitais são reais e que a partir deles podemos construir o mundo da química. Eles são a forma mais extensiva e unificadora de observar os fenômenos químicos". ${ }^{41}$ Assim, o problema proposto conduziu Scerri ${ }^{26}$ a formular a seguinte pergunta: "Podem os orbitais ser reais na química, mas não na física?". Parece claro que essa situação paradoxal tem consequências negativas para uma compreensão profunda da disciplina: os estudantes enfrentam a alternativa de viver em um tipo de "esquizofrenia conceitual" ou aceitar que a química descreve fenômenos meramente aparentes ou "metafóricos". 42

A partir dessas críticas, Scerri começou a mitigar sua posição, adotando uma "posição intermediária" entre o normativismo e o naturalismo: mesmo que os orbitais não possam ser observados de acordo com a mecânica quântica, os educadores podem empregá-los de forma realista, mas indicando cuidadosamente suas limitações. ${ }^{43}$ Porém quando o debate filosófico-científico parecia estar teoricamente definido em favor da interpretação antirrealista (ou seja, orbitais não são observados), diversos grupos experimentais continuaram reportando a visualização dos orbitais moleculares, reabrindo a controvérsia. ${ }^{44}$

Desde então, alguns autores argumentaram em favor de uma interpretação realista dos orbitais desde diversos marcos filosófi$\cos { }^{43,45}$ Em particular, argumentou-se que o problema dos orbitais é um problema conceitual que se refere tanto a átomos com um elétron ou com muitos elétrons. Em mecânica quântica, o conceito de orbital indica a função de onda do átomo que, como entidade matemática, não habita o mundo quântico. Em química molecular, o conceito de orbital se refere a uma região do espaço onde são encontrados com maior probabilidade os elétrons semiclássicos em torno do núcleo clássico. Em outras palavras, os orbitais não existem no mundo descrito pela mecânica quântica, mas sim existem no mundo descrito pela química molecular. Quando se abandona o pressuposto ontologicamente reducionista e se reconhece que todo objeto de conhecimento surge como a síntese entre a realidade independente ('númeno', nos temos kantianos) e o esquema conceitual que traz o sujeito cognoscente, admite-se, então, que a ontologia quântica é tão dependente teoricamente como a ontologia química molecular. E nessa ontologia, as entidades que a habitam, junto com suas propriedades, não necessitam de "legitimidade ontológica": são entidades pertencentes ao mundo da química molecular e sua existência objetiva não depende de suas relações interteóricas com teorias (supostamente) mais "fundamentais". ${ }^{46}$

\section{O PROBLEMA DO CONCEITO DE LIGAÇÃO QUÍMICA}

A noção de ligação constitui um dos conceitos centrais da química. Grande parte da química moderna se ocupa das propriedades e da dinâmica das ligações químicas. As teorias atuais sobre o tema surgem dos trabalhos de Irving Langmuir, Walther Kossel, ${ }^{47}$ e, especialmente, de Gilbert Newton Lewis. ${ }^{48}$ Com uma notável intuição, Lewis desenvolveu sua teoria vários anos antes do surgimento da mecânica quântica e do conceito de orbital. Em 1916, Lewis publicou seu artigo, The Atom and the Molecule, que permitiu compreender a natureza das ligações entre átomos não metálicos. Além disso, o artigo assentou as bases de nossa compreensão atual da estrutura molecular, que é outro conceito fundamental da química contemporânea. Com o estabelecimento da mecânica quântica, duas teorias físicas desenvolveram a descrição da ligação química em termos formais: a teoria da ligação de valência e a teoria dos orbitais moleculares.

A natureza da ligação química começa a ser discutida na filosofia contemporânea da química. ${ }^{49-51} \mathrm{Tal}$ como afirma Weisberg, ${ }^{51}$ ainda que tal conceito exerça um papel central nas previsões e explicações, ela não é uma noção simples de definir. De fato, encontram-se diversos enfoques teóricos, desde a clássica concepção de Lewis, para quem um par de elétrons era responsável por manter dois átomos unidos, formando uma ligação covalente, até as divergentes concepções da mecânica quântica, que colocam em evidência que a noção de ligação é um conceito difícil de elucidar.

Na nova literatura filosófica sobre o tema, o ponto de partida é a chamada concepção estrutural da ligação química. ${ }^{50}$ Ela considera que as ligações químicas são partes materiais da molécula responsáveis por manter espacialmente localizadas as relações submoleculares, entre centros atômicos individuais. Essa é a concepção de ligação que foi apresentada ao final do Século XIX e ela enfrenta dois desafios. O primeiro deles surge da incompatibilidade entre a ontologia da mecânica quântica e a ontologia da concepção clássica. Dado que, em princípio, os elétrons não podem ser distintos (princípios de identidade e individualidade), as descrições mecânico-quânticas não podem depender da identidade dos elétrons individuais. Nesse sentido, a deslocalização eletrônica em toda a molécula (de acordo com a teoria dos orbitais moleculares) apresenta uma imagem incompatível com a proposta de Lewis.

$\mathrm{O}$ segundo desafio à concepção estrutural tem origem na química computacional. Baseado nos trabalhos do químico quântico Charles Coulson, Weisberg afirma que a concepção estrutural está desafiada pela "robustez" das concepções mecânico-quânticas. ${ }^{51}$ Para esse autor, a concepção robusta da ligação química pode ser caracterizada assinalando que a ligação é uma região submolecular, direcional, de densidade eletrônica localizada entre os centros atômicos responsáveis por manter os átomos unidos. Isso permitiu a Weisberg: a) distinguir entre ligações covalentes e ligações iônicas, dada a restrição da direcionalidade; b) postular que é um fenômeno submolecular confinado às regiões entre os átomos; e c) identificar a ligação como uma força estabilizadora para a molécula, que se manifesta a partir da quantidade de energia necessária para separar os átomos (concepção energética da ligação). Em poucas palavras, o fenômeno da ligação é real, mas não as ligações em si mesmas. Essa análise foi fortemente criticada recentemente. Contudo, chegou-se a apelar à dimensão pragmática para defender a concepção estrutural, dado o êxito empírico em descobrir e sintetizar novas substâncias. ${ }^{52}$ Anteriormente, Linus Pauling também defendeu esse enfoque. ${ }^{33}$ Em virtude dessas considerações, parece natural, então, argumentar em favor de uma perspectiva pluralista para entender a natureza da ligação química. ${ }^{53}$

\section{OS PROBLEMAS DE FUNDAMENTOS DA TABELA PERIÓDICA}

A tabela periódica dos elementos é um ícone da ciência e, talvez, constitua o sistema mais natural de classificação da ciência em seu conjunto. O sistema periódico, que subjaz a tabela periódica, é uma das grandes ideias da química, já que propicia a forma de entender como reagem os elementos entre si, auxiliando a explicar as propriedades de cada elemento. Precisamente, tal noção possui um papel central na tabela periódica. Porém em relação à filosofia das ciências, 
como indica Eric Scerri, ${ }^{54}$ o conceito de elemento não é discutido de forma associada à investigação química ou mesmo ao ensino dessa disciplina. Com o estabelecimento social da filosofia da química como disciplina legítima de investigação, uma nova geração de filósofos da química, químicos e historiadores busca aclarar tal termo. Mas, surpreendentemente, tornou-se evidente o desacordo existente: ainda que haja um amplo consenso acerca de sua extensão (seu alcance), não ocorre o mesmo com a intenção (seu sentido) nem ainda com a terminologia empregada. ${ }^{55}$

O conceito de elemento pode ser compreendido a partir de duas concepções. A primeira delas, herança dos gregos antigos, é a concepção abstrata (ou metafísica), que considera os elementos como aquilo que subjaz ou serve de substrato às propriedades observáveis. A outra concepção considera os elementos como substâncias simples, ou seja, os elementos tangíveis e observáveis com que estamos familiarizados e que podem ser isolados, tais como ouro, mercúrio, oxigênio, etc. Essa relevante distinção é considerada no sistema francês de educação química, onde o termo 'elemento' é utilizado para denotar o sentido abstrato ou metafísico.

Retorna-se, então, à tabela periódica. Com uma ativa participação de químicos, físicos e filósofos da química, são vários os tópicos que são debatidos, a saber: qual é a origem da tabela periódica? Existe uma melhor forma de apresentar os elementos na tabela? Ela pode ser reduzida à mecânica quântica? Qual é o lugar adequado para o hidrogênio e o hélio? Que elementos devem fazer parte do grupo 3 ? Qual é o papel das tríades? A seguir, apresentam-se brevemente os debates sobre tais temas.

Há mais de 140 anos da publicação da primeira tabela periódica de Mendeleev, mais de mil variantes da mesma foram apresentadas e, ainda hoje, ela é objeto de incessantes discussões no plano epistemológico. O debate central apresentado aqui está relacionado com a questão da existência de uma melhor forma de localizar os elementos, ou seja, se existe uma melhor forma de representar o sistema periódico. ${ }^{56}$ Alguns autores afirmam que é irrelevante tentar encontrar uma única representação dos elementos que dê conta de todas as relações existentes entre os elementos; em outras palavras, não existe a melhor representação (com uma única posição para cada elemento) uma vez que há apenas uma questão de comodidade e de convenção. ${ }^{57}$ Entretanto, indicou-se também que deve existir uma forma ótima de ordenar os elementos em grupos de colunas. Isso implica que algumas representações do sistema periódico são superiores a outras. Em particular, o problema que apresenta a localização do hidrogênio e do hélio tem uma solução correta. Essa tensão existente entre tais posições é parte do antigo debate em filosofia conhecido como "instrumentalismo versus realismo", respectivamente.

Muitos autores sugeriram, também, que uma representação mais satisfatória seria dada se cada período começasse com valores de $n$ $+l$ (os dois primeiros números quânticos; a denominada "regra de Madelung") ${ }^{58,59}$ ao invés de utilizar apenas $n$, dado que, $n+l$ possui

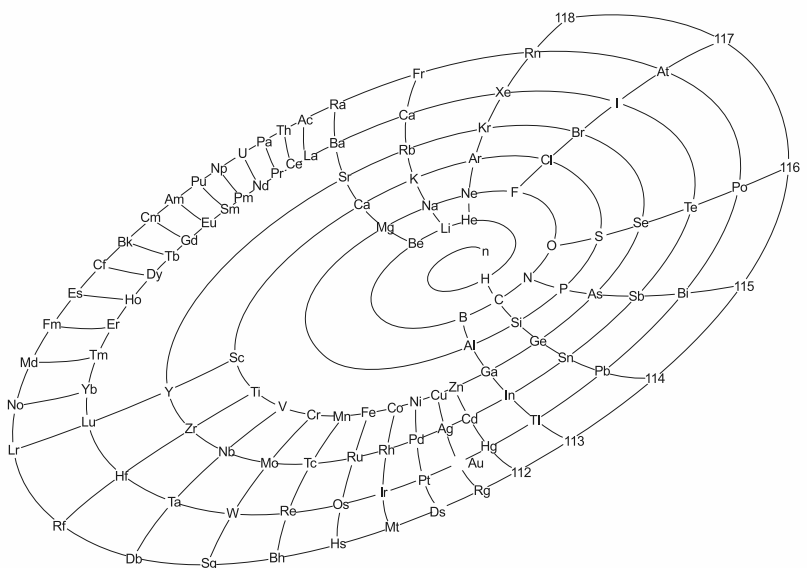

Figura 1. Tabela periódica tridimensional "galáxia química", adaptada de http://www.chemicalgalaxy.co. $u k /^{61}$

um status mais fundamental.

Apesar da representação bidimensional tradicionalmente aceita, alguns autores têm desafiado essa visão propondo sistemas periódicos tridimensionais, onde a ideia central é justamente prescindir de uma "tabela". Uma dessas propostas é chamada de Árvore dos Elementos, ${ }^{60}$ que coloca ênfase em semelhanças químicas que não são compreendidas na tabela bidimensional. Por exemplo, no grupo 13 se encontram elementos como boro, alumínio e gálio, cuja valência é 3 , mas existem outros elementos com igual valência (como escândio, ítrio e lutécio). No sistema de Dufour todos esses elementos são encontrados no mesmo plano bidimensional. Outro sistema tridimensional proposto é em forma de espiral (a denominada galáxia química, Figura 1), cuja vantagem está em eliminar as rupturas entre os gases nobres e os metais alcalinos, como ocorre na tabela periódica, ressaltando assim a continuidade entre os elementos. ${ }^{61}$

Além disso, várias tabelas bidimensionais foram propostas, cujas vantagens e desvantagens são objeto de um incessante debate. Uma delas é denominada tabela de degrau esquerdo (left-step, Figura 2), proposta por Charles Janet em 1929, com base em critérios estéticos e de acordo com a mecânica quântica. Ela foi revitalizada pelo educador químico Gary Katz, ${ }^{59}$ e atualmente alguns químicos estão argumentando em seu favor. ${ }^{62}$

Nessa tabela, o hélio é encontrado entre os metais alcalinos terrosos (uma vez que todos os elementos desse grupo possuem dois elétrons na camada de valência). Uma segunda característica é que o bloco $s$ completo (incluindo o hélio) foi colocado à direita da tabela periódica convencional. Isso evita os espaços existentes entre grupos de elementos, como berílio e boro ou magnésio e alumínio, tal como se encontra na tabela de longitude média. Tal tabela reflete fielmente a ordem de preenchimento dos elétrons nos átomos neutros dos elementos, de acordo com a regra de Madelung.

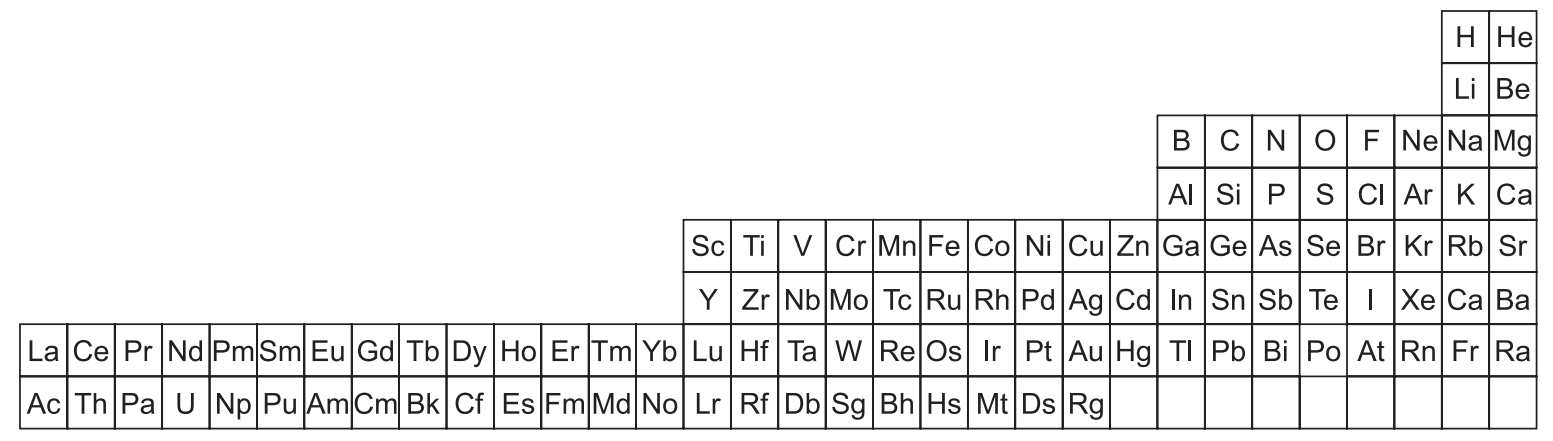

Figura 2. Tabela periódica de "escada à esquerda", adaptada de Katz $z^{59}$ e Bent e Weinhold ${ }^{62}$ 


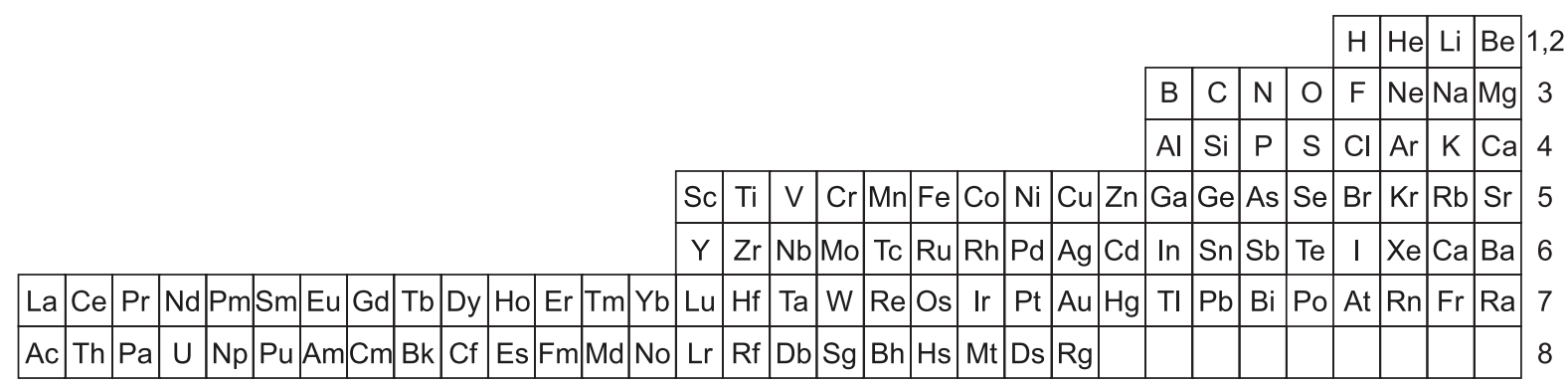

Figura 3. Tabela periódica de "escada à esquerda modificada", adaptada de http://goo.gl/TPSvJZ, conforme trabalho original de Charles Janet ${ }^{63}$

Recentemente foi resgatada uma proposta de tabela chamada de "escada à esquerda modificada" (Figura 3) que procura maximizar as tríades de número atômico, ${ }^{63}$ deixando o hélio entre os gases nobres - devido a tríade $\mathrm{He}(2), \mathrm{Ne}(10), \operatorname{Ar}(18)$ - e colocando o hidrogênio como parte dos halogênios, formando uma nova tríade: $H(1), F(9)$, $\mathrm{Cl}(17)$. Isso permite prescindir do período aparentemente anômalo na tabela periódica padrão. ${ }^{64}$ Porém, alguns autores negam existir algum dado relevante nas tríades de número atômico. ${ }^{65}$

Em função de suas propriedades, os elementos que são "problemáticos" de localizar adequadamente são, sem dúvida, o hidrogênio e o hélio. Em relação ao hidrogênio, são quatro as opções: a) deixá-lo no grupo 1 (metais alcalinos), ainda que "flutuando" sobre tal grupo, pois possui um elétron em sua camada de valência (como está na tabela periódica convencional); b) colocá-lo no grupo 17 (halogênios), uma vez que os átomos de $\mathrm{H}$ podem formar íons negativos, como ocorre com os elementos desse grupo ${ }^{66} \mathrm{c}$ ) colocá-lo no grupo 14 (do carbono), já que possui metade de sua camada de valência completa (2 elétrons) ${ }^{67}$ ou ainda d) removê-lo da tabela e o deixar "flutuando" sobre ela, devido às anomalias que impossibilitam localizá-lo em um grupo específico. ${ }^{68}$

A posição do hélio na tabela oferece inconvenientes similares. As opções seguintes são debatidas: a) deixá-lo no grupo 18 (gases nobres), tal como é encontrado na tabela periódica padrão, uma vez que ele é extremadamente inerte; ${ }^{69}$ b) removê-lo da tabela e o deixar "flutuando" sobre ela, como o hidrogênio; ${ }^{68}$ ou ainda c) incluí-lo no grupo 2 (alcalinos terrosos) pois possui 2 elétrons em sua camada de valência.

Outro interessante debate envolve a questão dos elementos que devem formar o grupo 3. Na tabela periódica padrão se encontra os elementos escândio (21), ítrio (39), lantânio (57) e actínio (89). Mas alguns químicos e filósofos da química indicam que esses dois últimos elementos deveriam ser substituídos pelo lutécio (71) e pelo laurêncio (103), já que com eles se forma a tríade "perfeita" de números atômicos Y(39), Lu(71) e Lw(103). ${ }^{64}$ Esse reposicionamento foi, também, sugerido sobre bases físicas e químicas ${ }^{70}$ tendo sido aplicado em muitos livros didáticos e na ilustração de tabelas periódicas, mesmo que exista certa resistência com tal substituição. ${ }^{71}$

Além disso, existem dois enfoques atuais acerca do problema do reducionismo na tabela periódica. $\mathrm{O}$ primeiro se refere a um enfoque matemático do sistema periódico, utilizando estudos de similaridade, ${ }^{72}$ de teoria de grupos ${ }^{73}$ e da teoria da informação. ${ }^{74}$ Alguns autores começaram a analisar o significado desses trabalhos, ${ }^{75}$ mas ainda resta muito por fazer. ${ }^{76} \mathrm{O}$ segundo enfoque está relacionado com a aplicação da mecânica quântica à tabela periódica. Scerri sugere que a teoria quântica proporciona uma explicação parcial para sua forma e existência, sendo adequada para reduzir propriedades individuais dos elementos, mas não para captar propriedades globais (o pertencimento dos elementos a certos grupos, por exemplo). ${ }^{64}$ Desde o ponto de vista dos físicos, os elétrons da camada de valência são os responsáveis pelas propriedades químicas. Contudo, esse enfoque é inadequado para decidir o lugar do hidrogênio na tabela ou os elementos pertencentes ao grupo 3 .

$\mathrm{O}$ conjunto dos quatro números quânticos $(n, l, m, s)$ permite predizer que as camadas do átomo podem conter um máximo de 2, 8, 18 ou 32 elétrons, um dado que concorda com a extensão dos períodos da tabela. Porém, a mecânica quântica não justifica a repetição das extensões dos períodos, exceto a primeira. Nesse sentido é interessante destacar o debate atual em relação ao status da chamada regra de Madelung, que indica a ordem para completar os orbitais nos átomos em fase gasosa, a saber:

$$
1 s<2 s<2 p<3 s<3 p<4 s<3 d \ldots
$$

onde a soma de $n+l$ se refere à soma dos dois primeiros números quânticos para cada um dos orbitais assinalados. Nesse sentido, existe a questão se tal regra foi derivada dos primeiros princípios. Enquanto alguns autores afirmam que a regra é semiempírica, ${ }^{64,77}$ outros não deixam de sustentar uma posição reducionista. ${ }^{73,78}$ Ainda, Schwarz e Rich sugerem que a regra de Madelung é relativamente irrelevante na química, uma vez que se refere a configurações eletrônicas de átomos não unidos em fase gasosa. ${ }^{79}$

\section{OS MODELOS E AS EXPLICAÇÕES EM QUÍMICA}

O debate sobre os modelos constituem um aspecto central da organização e da prática na química contemporânea. ${ }^{80}$ Os químicos constroem e refinam modelos não apenas para compreender fenômenos diversos, mas também para guiar seus futuros experimentos. Por exemplo, os modelos moleculares propiciam valiosas informações acerca dos requisitos geométricos em uma reação química. As propriedades físicas e químicas dos ácidos e das bases são explicadas através dos modelos de Arrhenius, de Brønsted-Lowry ou de Lewis, por exemplo. Na cinética química o mecanismo de reação química foi explicado segundo diversos modelos no decorrer da história da química. ${ }^{81}$ Por tudo isso, Erduran destaca a importância do uso de modelos na educação em química, como ferramenta para a aprendizagem e elaboração conceitual da disciplina. ${ }^{82}$

Dessa maneira, a natureza dos modelos e das explicações em química é uma área de interesse crescente na filosofia da química contemporânea, uma vez que o mundo químico provê exemplos numerosos e variados aos filósofos da ciência interessados pelo tema. Como são as explicações na química moderna? Elas são autônomas em relação às explicações da física? Qual é a natureza dos modelos químicos?

Os modelos científicos são um tema de análise filosófica ${ }^{83} \mathrm{e}$ os filósofos da química têm mostrado um interesse particular pelo papel exercido pelos modelos na compreensão teórica e na prática científica. ${ }^{84}$ Porém, existem muitas confusões acerca do significado do termo modelo. ${ }^{85}$ Tomasi trata do uso dos modelos na química quântica e sugere a necessidade de aclaração semântica sobre o termo 'modelo', que é elemento básico de cada pesquisa em química quântica. ${ }^{86}$ Nesse sentido, os modelos podem ser classificados como 
'material' ou 'abstrato'. Tanto os modelos materiais quanto os modelos abstratos podem ser, além disso, classificados como 'icônico', 'analógico' e 'simbólico'. Assim, esse autor propõe uma taxonomia para os diferentes tipos de modelos usados na química teórica. A estrutura básica dos modelos na química teórica envolveria: a) modelo material; b) modelo físico; c) modelo matemático; e d) modelo interpretativo. Além disso, existiria uma hierarquia de modelos, pois a pesquisa científica estaria baseada em modelos de modelos, onde um modelo é adicionado para ser utilizado e elucidar alguns pontos específicos de outro modelo. A partir dessa proposta, o autor busca centrar o foco na investigação sobre o papel dos modelos interpretativos na química teórica.

Del Ré sugere que os modelos físicos são ferramentas essenciais não somente para a descrição do mundo "exterior", mas para a própria cognição humana das coisas, especialmente daqueles fenômenos que não são diretamente acessíveis pelos sentidos. ${ }^{28} \mathrm{O}$ modelo molecular de bolas e palitos (ou sua variante de bolas e molas) é o exemplo mais instrutivo de um modelo físico. Nesse modelo, o significado da analogia é claro, as propriedades geométricas e mecânicas do modelo macroscópico são assumidas como correspondentes às propriedades da molécula real. Nesse sentido, Lazslo sugere que os modelos moleculares podem ser interpretados como brinquedos, que auxiliam a exploração e a construção da realidade, inserindo os modelos físicos no âmbito da discussão geral sobre o papel da representação em química. ${ }^{87}$ Assim, entende-se que os modelos teóricos de objetos e de fenômenos empíricos possuem várias funções na ciência, sendo que um dos mais importantes é o de representação. ${ }^{88}$

Bhushan e Rosenfeld enfatizam os aspectos metafóricos dos modelos analógicos e reconhecem que os cientistas constroem e avaliam os modelos de duas diferentes formas. ${ }^{89}$ Alguns modelos realmente reproduzem os dados e seu principal objetivo é a previsão, porém outros modelos auxiliam a experimentar a natureza fundamental dos fenômenos. Nesse sentido, os modelos possuem uma dupla função para a compreensão dos fenômenos. O sentido interpretativo é aquele que seria o metafórico. Em relação ao modelo molecular de bolas e molas (ou palitos), para enfatizar o sentido metafórico caberia perguntar: uma bola é como o átomo? Uma mola é como uma ligação química? De que maneira? Em que aspectos? Nesses casos, o reconhecimento dos limites do modelo é desejável.

Francoeur sugere que os modelos moleculares físicos (que ele chama de modelos $_{\mathrm{m}}$ ) devem ser diferenciados dos modelos conceituais matemáticos (chamados de modelos ) que são utilizados para a compreensão e controle, em casos favoráveis, de sistemas complexos. ${ }^{85}$ Em uma análise de eventos históricos, o autor procurou ilustrar como no início da estereoquímica os químicos utilizaram os modelos $_{\mathrm{m}}$ para resolverem problemas em vários contextos de pesquisa. Nessa ocasião, os $\operatorname{modelos}_{\mathrm{m}}$ foram utilizados como uma parte integral da articulação do conhecimento dos químicos com a experiência das estruturas moleculares como entidades conceituais. Além disso, uma análise realizada por Fisher mostrou que os $\operatorname{modelos}_{\mathrm{m}}$ em físico-química orgânica são empregados para atualizar ou aplicar teorias em situações concretas, para corrigir teorias e para modelar processos quando a teoria não apresenta dados adequados. ${ }^{83}$

O pensamento realizado com suporte nas estruturas químicas pode ser considerado uma marca registrada dos químicos, tanto quanto os tubos de ensaio, os béqueres ou as colunas de destilação. ${ }^{90} \mathrm{~A}$ maioria dos cientistas, senão todos, utiliza a imaginação visual para resolver problemas, de forma a selecionar e organizar as suas informações ou a encontrar analogias para pensar. Mas, entre os cientistas, os químicos são extraordinários, pois possuem um vernáculo icônico, que são as fórmulas e as estruturas químicas. Assim, rotineiramente, as explicações partem de uma escala submicroscópica para o observável. Por exemplo, a partir do modo como os elétrons estão distribuídos em uma molécula de pigmento é possível supor sua cor, ou devido ao potencial eletrostático de uma molécula se pode prever sua atividade farmacológica.

Na filosofia da ciência contemporânea, a característica criativa (pode-se dizer construtiva) do processo de modelagem teórica nas ciências empíricas não é mais, normalmente, questionada. Entretanto, estabelecer se há uma aderência à versão realística ou antirrealística do construtivismo depende amplamente do modo como a questão da representação é explicitada. Por exemplo, Zeidler indica que por muitas décadas os químicos observaram os modelos moleculares como uma forma de representar moléculas reais e suas propriedades, porém, novos dados experimentais sugerem novas conceituações teóricas e o modelo rígido é substituído por um modelo dinâmico em que a estrutura molecular muda com a influência das condições do entorno.$^{88}$ Assim, do ponto de vista do modelo dinâmico, a estrutura molecular depende das circunstâncias experimentais e de mensuração.

Porém, admitindo-se uma estreita relação entre a química e a física, pode-se pensar que os modelos e as explicações em química devem ser abordados, também, desde um reducionismo epistemológico. Ou seja, a física fundamental deveria explicar satisfatoriamente a natureza dos modelos químicos e oferecer explicações mais gerais e fundamentais do que as explicações químicas. Entretanto, alguns autores ressaltam que mesmo quando as regularidades químicas estejam instanciadas em processos físicos fundamentais pode ser mais útil explicá-las e descrevê-las em um nível químico. Em outras palavras, as explicações e os modelos da química são genuinamente específicos do nível químico considerado e, portanto, são autônomos em relação àqueles da física. ${ }^{26}$

De acordo com Earley, ${ }^{91}$ a química e a emergente disciplina da filosofia da química tem ambas contribuído para a contínua discussão filosófica acerca da natureza da explicação científica. O tema da explicação química foi, amplamente, abordado em um número especial no Annals of the New York Academy of Sciences, editado a partir de um simpósio promovido pela International Society of the Philosophy of Chemistry and Biochemistry. ${ }^{91,92}$ Nesse seminário, a discussão sobre a explicação química está bem apresentada, porém o foco é mais amplo do que aquele restrito ao âmbito da filosofia.

As explicações codificam os objetivos e os valores de comunidades científicas particulares, dizendo aos praticantes o que eles devem querer saber sobre o mundo e como eles devem pensar para chegar lá. Internalizando esses padrões de pensamento, consistentes com tais objetivos e valores, o discurso explicativo é crucial para a formação coesa das disciplinas científicas. ${ }^{93}$ Conforme Weisberg, ${ }^{94}$ a relação entre os modelos e a explicação química pode ser evidenciada com a seguinte norma: se você quer produzir explicações químicas, então você deve construir modelos qualitativos. De acordo com Fisher a utilização ubíqua dos modelos em química é um indicativo de sua importância para a explicação química. ${ }^{95}$ Mas desde as primeiras teorias filosóficas da explicação se sabe que o entendimento propiciado por uma explicação depende das características do contexto em que ela é dada, mesmo que seus autores procurem se abstrair de suas características pragmáticas. Estabelecida a audiência alvo, os fatores relevantes incluem: i) o nível de conhecimento de base assumido; ii) a natureza, apresentação e plausibilidade da informação explicativa; iii) a saliência das demandas explicativas particulares; e iv) de forma mais controversa, a relevância explicativa. ${ }^{96}$

Quando se questiona sobre as semelhanças e diferenças entre as explicações químicas e as explicações de outras ciências, Brown indica que é preciso considerar a profunda natureza metafórica das explicações científicas em geral. ${ }^{97}$ Nesse sentido, utilizando exemplos da química orgânica, ele argumenta que os modelos empregados pelos químicos como instrumentos explicativos são metafóricos em natureza e possuem um caráter distinguível das representações explicativas empregadas em outros domínios da ciência. Com a mesma temática, 
Goodwin apresenta uma excelente descrição fenomenológica da explicação em química orgânica, ${ }^{98}$ e Del Ré explora a relação estreita entre os mecanismos de reação e a explicação química. ${ }^{16}$

Desde outro ponto de vista, Stemwedel examina o papel que o conceito de causalidade joga na prática da química, ${ }^{99}$ analisando como os químicos utilizam o verbo causar em suas explicações, ${ }^{100}$ focalizando em particular os modos de identificar e de descrever as conexões causais. Esse também foi um tema de análises produzidas por um grupo brasileiro que reuniu educadores químicos e linguistas. ${ }^{101}$

Nesse sentido, Stemwedel questiona se no âmbito da química efetivamente é necessário falar acerca das causas, ${ }^{100}$ ou seja, se o conceito de causalidade seria alguma coisa a qual os químicos poderiam dispensar. Em sua resposta, sugere que a química é um emaranhado de projetos de descrição, de previsão, de controle e de explicação, que interatuam de diversas maneiras importantes. Para levar esses projetos adiante, os químicos utilizam um conceito de causalidade que recai sobre as conexões estruturais. São essas conexões, não importa se simples ou complexas, que explicam os fenômenos observáveis. Capturá-las, justamente, em modelos amplia o poder de previsão e permite ao químico realizar intervenções particulares que produzirão os resultados desejáveis. ${ }^{99}$

Assim, Harré enfatiza que um dos usos do termo 'explicação' denota a descrição dos mecanismos causais ou a constituição de um mecanismo causal que traz certo efeito ou produz dada substância ou produto. ${ }^{102} \mathrm{~A}$ explicação das reações químicas em termos de mecanismos está em conformidade com o esquema padrão das explicações científicas: modelando um dado sistema (por exemplo, considerando somente uma ou poucas moléculas em um ambiente padrão) e mostrando como certas regras gerais funcionam (por exemplo, as leis de valência). Nesse caso, os mecanismos são essenciais para a conversão de informações estruturais em informações sobre as taxas de reação (velocidades de reação). As questões sobre as taxas de reação são geralmente respondidas apelando aos fatos sobre a energia dos estados de transição da reação. Os mecanismos de reação parecem estar relacionados ao processo causal pelo qual as transformações ocorrem. Assim, de certa forma, esse tipo de explicação reforça a ideia do papel central que o processo causal desempenha nas explicações científicas.

Sobre as pesquisas feitas com as explicações, ${ }^{103}$ entende-se que essa temática confere uma possibilidade para explorar como os estudantes interpretam as ideias e os modelos científicos e como eles constroem relações entre os diferentes conceitos. Para muitos professores de ciências, a habilidade de um estudante gerar esboços de explicações é uma marca da compreensão significativa. ${ }^{104}$ É interessante fazer a diferença entra as explicações disciplinares (científicas) e as explicações didáticas (do ensino de ciências). As explicações disciplinares têm a intenção de elucidar e prever o fenômeno social e natural, elas são conduzidas pelas teorias e pelas evidências e são enquadradas por certas convenções retóricas de um dado domínio. Por outro lado, as explicações didáticas são planejadas para ensinar ou comunicar um aspecto particular do conhecimento. Esses tipos de explicações são contribuições que os professores e os livros didáticos oferecem para o processo de aprendizagem e são ferramentas poderosas para ajudar os estudantes a entender conceitos, eventos e procedimentos científicos. ${ }^{105}$

Definitivamente, é possível compreender o crescente interesse dos filósofos da química por esse tópico, já que a química, por sua própria natureza, envolve explicações muito mais específicas que no caso da física, dada a ampla variedade de substâncias existentes e a grande diversidade de reações que elas propiciam.

\section{O VÍNCULO COM A EDUCAÇÃO QUÍMICA}

Portanto a química é uma disciplina que é dominada pelo uso de modelos. Em consequência, o ensino de química envolve, também, o ensino de modelos, alguns relacionados à própria disciplina, outros vindos de disciplinas relacionadas, como a física ou a bioquímica. Muitos modelos em química são derivados de outros modelos, por exemplo, a teoria atômica é usada para desenvolver ideias sobre moléculas e cristais, embora ela mesma derive de um modelo de natureza da matéria. Uma complicação adicional surge quando o cientista ou o professor, que são manipuladores experientes de modelos, esquece-se que está comunicando um modelo, muitas vezes apresentando um modelo consensual como se ele fosse uma entidade real.

Assim, geralmente, a química continua sendo considerada pelos estudantes como uma disciplina difícil. Isso é compreensível na medida em que a aprendizagem da química exige que eles operem e inter-relacionem três níveis diferentes de pensamento: a) o nível macro (tangível), b) o nível micro (atômico e molecular), e c) o nível simbólico e matemático. ${ }^{106}$ Porém, durante os últimos anos, a investigação sobre a educação química realizou grandes avanços, entre eles: a utilização de ferramentas tecnológicas, a modificação da estrutura da disciplina escolar, a incorporação de resultados de estudos cognitivos, o recurso ao construtivismo pedagógico na química, a melhoria do trabalho de laboratório, entre outros. Entretanto, tais avanços resultaram pouco influentes sobre o efetivo ensino da química, como demonstram as avaliações nacionais de desempenho dos estudantes, apesar da notável melhoria dos livros didáticos, que recentemente incorporaram muitas das proposições da comunidade dos educadores químicos.

Por outra parte, o grande êxito alcançado pela mecânica quântica teve e ainda tem um enorme impacto sobre o ensino da disciplina: em particular, existe um uso crescente dos princípios da física fundamental para explicar a estrutura atômica e o sistema periódico dos elementos. Esse enfoque de ensino sobrepõe um aspecto que se deve levar em conta: mesmo quando se admite a tese segundo a qual a química é essencialmente governada pelas leis da mecânica quântica, é necessário enfatizar os aspectos qualitativos dos processos químicos e a diversidade dos fenômenos químicos observados, mantendo um equilíbrio entre esses dois enfoques. ${ }^{26}$ Tais concepções, ambas vigentes na atual metodologia de ensino da química, são objeto de um contínuo debate na literatura contemporânea. ${ }^{42}$

Frente a essa situação, a filosofia da química pode (e deve) converter-se em um novo recurso para os docentes de ciências, especificamente de química. Dado que a história e a filosofia da ciência se encontram implícitas na própria química, ${ }^{107}$ os educadores deveriam contar com os meios para comunicar em suas aulas explícitos argumentos filosóficos, além dos usuais recursos matemáticos e físicos. Como foi demonstrado empiricamente com outras disciplinas científicas, a reflexão filosófica acerca da natureza do campo de estudo facilita a aprendizagem conceitual da química. Nesse sentido, Scerri afirma: "Não é suficiente treinar os educadores em química apenas nos conteúdos dos cursos, e talvez oferecer alguma coisa de psicologia educativa. Os docentes de química necessitam ser introduzidos no estudo da própria natureza da química" ${ }^{108}$ Por isso é desejável que os avanços na investigação dos diferentes tópicos atuais na filosofia da química sejam utilizados em atividades de formação de professores. Desse modo, os docentes poderão incorporar não somente uma nova ferramenta pedagógica, mas também, uma concepção mais ampla e profunda de sua própria disciplina.

Porém, a experiência aponta que quando são abordadas discussões filosóficas nos cursos de formação inicial ou continuada de professores de química são, geralmente, utilizados autores que se apoiam sobre exemplos relacionados à física. ${ }^{109}$ Esse é o caso do sucesso das ideias de paradigma a partir da visão de Thomas Kuhn, claramente um filósofo da ciência que utilizou exemplo da física, dada a maturidade dessa disciplina. O mesmo se pode dizer da presença nas discussões 
filosóficas com os futuros professores de autores como Imre Lakatos (que trata do núcleo duro, das hipóteses acessórias e das heurísticas positivas relacionadas aos programas de pesquisa), Paul Feyerabend (acerca da discussão sobre o papel do método científico), Karl Popper (sobre a distinção entre teorias científicas legítimas ou não, a partir do critério de falseabilidade) entre outros. No Brasil, chama atenção a forte presença de Gaston Bachelard, que poderia ser visto como um filósofo da química, devido à sua formação, embora a maior parte de sua obra esteja relacionada à análise filosófica do desenvolvimento da microfísica no começo do Século XX. ${ }^{110} \mathrm{O}$ mesmo sucesso que faz a ideia de paradigma, também o faz, junto ao ensino de química, a ideia de obstáculo epistemológico de Bachelard.

Essas posições filosóficas não devem ser descartadas dos cursos de formação de professores de química. Em uma perspectiva de discussão de uma filosofia da ciência mais geral, ou em uma primeira aproximação às discussões filosóficas, esses autores são de grande utilidade. O problema reside em considerar que a formação filosófica do professor de química seria contemplada apenas com essas discussões. Como defendido anteriormente, a química como ciência impõe uma agenda de discussão que é própria da filosofia da química. Os problemas que nossa ciência suscita só podem ser abordados dentro de uma filosofia específica, que é a filosofia da química, que tem acumulado nesses últimos 15 anos uma reflexão bastante ampla e profunda. Então o que se deve considerar como pontos importantes para serem discutidos nos programas de formação inicial e continuada de professores de química?

O primeiro ponto que parece crucial discutir com os futuros professores deve ser o do status da química frente às outras ciências da natureza. É necessário defender a autonomia da química em relação à biologia e à física, especialmente, frente à mecânica quântica. $\mathrm{O}$ aspecto fulcral aqui é o tema da redução. Há posições assumidas por químicos que apontam para um discurso de "modo reducionista", como indica Hoffmann. ${ }^{111}$ Há posições intermediárias como a de Scerri, ${ }^{15}$ que fala de certa ambiguidade em relação a essa questão da redução. Esse autor afirma que a química estaria reduzida e ao mesmo tempo não-reduzida pela mecânica quântica. No extremo oposto, há o trabalho de Lombardi e Labarca, ${ }^{21}$ que defendem não só a autonomia epistemológica da química frente à mecânica quântica quanto também no nível ontológico, ou seja, no nível das entidades químicas frente às entidades quânticas.

Em um segundo momento, parece impensável evitar a discussão sobre a "ética na química". O cotidiano da química tem como característica a identificação e a análise de substâncias ou moléculas. Porém, a síntese de novas moléculas requer certo cuidado na medida em que se introduz no mundo natural materiais complexos que antes não existiam. Segundo Schummer, ${ }^{112}$ aqui há uma discussão ética importante. Afinal qual a responsabilidade do químico sintético em relação ao que produz? Aqui também seria pertinente a discussão sobre o estabelecimento de patentes, ou seja, de quem é o conhecimento? Quem é o responsável pelos produtos do conhecimento químico? Nesse item, relativo à responsabilidade sobre a produção de conhecimento e de produtos químicos, também seria pertinente a discussão sobre o plágio, sobre a replicação de trabalhos da mesma natureza, que seria uma forma de auto-plágio, sobre o financiamento das pesquisas, etc. Questões chaves são: quem decide? Sob quais critérios?

Uma discussão correlata, mas não menos importante, seria a relação da química com a sociedade. Considerando alguma continuidade entre a história da alquimia e o surgimento da química moderna há intercorrências importantes. Ou seja, a herança do que teve de bom ou de ruim na relação da alquimia com a sociedade deve ser assumida pelos químicos atuais. No entanto, existem historiadores como Afonso-Goldfarb que sustentam que duas racionalidades governam a alquimia e a química moderna, tendo a última surgido com a "morte" da primeira. ${ }^{113}$ Há filósofos e historiadores da química que consideram que a relação da alquimia com as sociedades da época foram tensas, para não dizer ruins. Promessas de curas não cumpridas, de transformações irrealizáveis, fizeram da alquimia uma atividade mais próxima de uma seita secreta do que propriamente uma protociência que veio resultar na química moderna. Porém, também a química moderna não tem prometido muitas coisas à sociedade que não consegue realizar? A visão que as sociedades atuais têm de nossa ciência prima pela boa imagem? Ou a imagem da química junto à sociedade é associada a ações deletérias como poluição, radiação e de interferência no chamado "mundo natural"?

Dentro dessa agenda, deve-se incluir a discussão sobre os modelos na química. Nesse caso podemos discutir a congruência entre os modelos na química e as teorias químicas como discute Tomasi. ${ }^{86}$ Os professores precisam refletir sobre como os modelos, largamente utilizados na química, são entendidos como entidades de existência real. Por exemplo, os realistas científicos ironizam os químicos que acreditam na existência real de orbitais, taxando-os de realistas de tipo ingênuo. Entende-se ser necessário debater com professores de química de todos os níveis de ensino o papel que cumprem os modelos na ciência, em geral, e na química, em particular.

Há vários outros aspectos do domínio da filosofia da química que merecem ser discutidos nos programas de formação de professores de química, por exemplo: a nanotecnologia, suas promessas para a sociedade e a relação com o mundo natural; ou os aspectos estéticos sobre a semiótica da química. Assim, compreende-se que a formação de professores e o ensino da química serão bastante beneficiados com o conhecimento acumulado nessa nova disciplina denominada Filosofia da Química.

\section{CONCLUSÕES E PERSPECTIVAS}

Há pouco mais de uma década a filosofia da química ainda esperava pelo seu reconhecimento como subdisciplina da filosofia da ciência. Como consequência, nos encontros acadêmicos os filósofos da química costumavam ser confinados às sessões correspondentes à filosofia das ciências físicas. Essa situação está mudando quase completamente. $\mathrm{O}$ crescente interesse de químicos, historiadores e filósofos da ciência pelos problemas da ciência química resultou em um forte impulso da filosofia da química.

Para além dos tópicos comentados, uma ampla variedade de temas é objeto de reflexão filosófica. Entre eles podemos citar o estatuto das leis e teorias químicas, as classes naturais, a visualização, a ética da química, assim como tópicos metodológicos como experimentação, instrumentação e síntese química. A nanotecnologia é também um tema de interesse crescente, no qual a química está particularmente envolvida. Por outra parte, nos últimos anos têm sido redescoberto interessantes trabalhos filosóficos sobre a química de pensadores clássicos como Aristóteles, Immanuel Kant, Georg W. F. Hegel, Pierre Duhem e Ernest Cassirer, tanto como os escritos filosóficos de renomados químicos como Benjamin Brodie, Wilhelm Ostwald, František Wald, Edward Caldin, Friedrich Paneth e Michael Polanyi. ${ }^{114}$ Por fim, entende-se que essa pluralidade temática não apenas garante o definitivo estabelecimento social da filosofia da química, como também oportuniza uma compreensão mais ampla de uma ciência natural como a química.

\section{AGRADECIMENTOS}

Martín Labarca agradece o apoio do Consejo Nacional de Investigaciones Científicas y Técnicas (CONICET) e da Agencia Nacional de Promoción Científica y Tecnológica (FONCyT) da Argentina. 


\section{REFERÊNCIAS}

1. van Brakel, J.; Synthese 1997, 111, 253.

2. Atkins, P.; Jones, L.; Princípios de Química, Bookman: Porto Alegre, 2006; Schummer, J.; Hyle 1998, 4, 129.

3. Liegener, C. M. y Del Re, G.; Epistemología 1987, 10, 269.

4. Trata-se do número 3 do volume 111, de junho de 1997, da revista Synthese.

5. Popper, K.; A Lógica da Pesquisa Científica, Cultrix: São Paulo, 1972.

6. Kuhn, T.; A Estrutura das Revoluções Cientificas, Perspectiva: São Paulo, 1975.

7. Lakatos, I.; Falsificação e Metodologia dos Programas de Investigação Científica, Edições 70: Lisboa, 1999.

8. Feyerabend, P.; Contra o Método. Francisco Alves: Rio de Janeiro, 1977.

9. Um bom exemplo é $O$ pluralismo coerente da química moderna, de Gaston Bachelard, cuja obra original é de 1932.

10. Para uma discussão detalhada: van Brakel, J.; Philosophy of Chemistry. Between the Manifest and the Scientific Image, Leuven University Press: Leuven, 2000, cap. 1.

11. Dirac, P. A. M.; Proc. Royal Soc. 1929, A338, 714.

12. Psarros, N.; Found. Sci. 1998, 1, 183.

13. Vancik, H.; Found. Chem. 1999, 1, 242.

14. Schummer, J.; Endeavour 2003, 27, 37; Bensaude-Vincent, B. Faut-il Avoir Peur de la Chimie?, Empêcheurs de Penser em Rond : Paris , 2005.

15. Baird, D.; Scerri, E.; McIntyre, L.; Philosophy of Chemistry: Synthesis of a New Discipline, Springer: Dordrecht, 2006; Bhushan, N.; Rosenfeld, S.; Of Minds and Molecule,. Oxford University Press: New York, 2000; Scerri, E. R.; The Periodic Table - Its Story and Its Significance, Oxford University Press: New York, 2007; van Brakel, J.; Em Of Minds and Molecules; Bhushan, N.; Rosenfeld, S., eds.; Oxford University Press: New York, 2000, pp. 162-184; van Brakel, J.; Ruthenberg, Klaus; Stuff - The Nature of Chemical Substances, Königshauen \& Neumann: Würzburg, 2008.

16. Del Ré, G.; Annals N.Y. Acad. Sci. 2003, 988, 133.

17. Bunge, M.; Z. Allg. Wiss. Theorie 1982, 8, 209.

18. Nye, M. J.; From Chemical Philosophy to Theoretical Chemistry, University of California Press: Berkeley, 1993.

19. Bader, R. F. W.; Int. J. Quant. Chem. 2003, 94, 173.

20. Lombardi, O.; Labarca, M.; Diálogos 2004, XXXIX, 51.

21. Lombardi, O.; Labarca, M.; Found. Chem. 2005, 7, 125.

22. Woolley, R. G.; Am. Chem. Soc. 1978, 100, 1073.

23. Primas, H.; Chemistry, Quantum Mechanics, Reductionism, Springer: Berlin, 1983.

24. Weininger, S. J.; J. Chem. Educ. 1984, 61, 939.

25. Woolley, R. G.; J. Chem. Educ. 1985, 62, 1082.

26. Scerri, E. R.; J. Chem. Educ. 2000, 77, 522.

27. Ramsey, J.; Synthese 1997, 111, 233.

28. Del Ré, G.; Hyle, 2000, 6, 5.

29. Schummer, J.;. Educ. Quím. 1999, 10 (2), 92.

30. Bader, R. F. W.; Atoms in Molecules: A Quantum Theory, Oxford Press: New York, 1990; Trindle, C.; Israel J. Chem. 1980, 19, 47; Sutcliffe, B.; J. Mol. Stru. 1992, 259, 29.

31. Sukumar, N.; Found. Chem. 2008, 11, 7.

32. Edminston, C.; J. Chem. Educ. 1992, 69, 600; Ogilvie, J. F.; J. Chem. Educ. 1990, 67, 280; Simons, J.; J. Chem. Educ. 1991, 68, 131; Tsarpalis, G.; J. Chem. Educ. 1997, 8, 922.

33. Pauling, L.; J. Chem. Educ. 1992, 69, 519.

34. Zuo, J. M.; Kim, M.; O’Keefe, M.; Spence, J. C. H.; Nature 1999, 401, 49.

35. Jacoby, M.; Chem. Eng. News 1999, 77, 8; Yam, P.; Sci. Am. 1999, 281, 28.

36. Zurer, P.; Chem. Eng. News 1999, 77, 38.
37. Humphreys, C. J.; Nature 1999, 401, 49.

38. Scerri, E. R.; J. Chem. Educ. 2000, 77, 1492; Scerri, E. R.; Phil. Sci. 2001, 68, S76; Wang, S-G.; Schwarz, W.H.E.; Angew. Chem. Int. Ed. 2000, 39, 1757.

39. Spence, J. C.; O'Keefe, M.; Zuo, J. M.; J. Chem. Educ. 2001, 78, 877.

40. Richman, R.; Found. Chem. 1999, 1, 175.

41. Cardellini, L.; J. Chem. Educ. 2007, 84, 1631.

42. Lombardi, O.; Labarca, M.; J. Chem. Educ. 2007, 84, 187.

43. Scerri, E. R. Em Philosophy of Chemistry: Synthesis of a New Discipline; Baird, D., Scerri, E.; McIntyre, L., eds. Springer: Dordrecht, 2006, pp.119-128.

44. Brion, C.; Cooper, G.; Zheng, Y.; Litvinyuk, L.; McCarthy, I.; Chem. Phy. 2001, 70, 13; Itatani, J.; Levesque, J.; Zeidler, D.; Niikura, H.; Pépin, H.; Kieffer, J.; Corkum, P.; Nature 2004, 432, 867; Litvinyuk, I.; Zheng, Y.; Brion, C.; Chem. Phy. 2000, 253, 41.

45. Crasnow, S.; Phil. Sci. 2000, 67, 114.

46. Labarca, M.; Lombardi, O.; Found. Chem. 2010, 12, 149; Labarca, M.; Lombardi, O.; Principia 2010, 14, 309.

47. Para a evolução histórica da noção: Sutcliffe, B.; Int. J. Quan. Chem. 1996, 58,645

48. Lewis, G. N.; J. Am. Chem. Soc. 1916, 38, 762; Lewis, G. N.; Valence and the Structure of Atoms and Molecules, Chemical Catalog Company: New York, 1923.

49. Berson, J.; Phil. Sci. 2008, 75, 947; Hettema, H.; Found. Chem. 2008, 10, 135; Nascimento, M.A.C.; J. Braz. Chem. Soc. 2008, 19, 245.

50. Hendry, R. F.; Phil. Sci. 2008, 75, 909; Hendry, R. F.; Em Philosophical Issues in the Sciences: Launch of the European Philosophy of Science Association, Dorato, M.; Redei, M.; Suarez, M., eds.; Springer: Berlin, 2010, pp. 117-127.

51. Weisberg, M.; Phil. Sci. 2008, 75, 932.

52. Stemwedel, J.; Philosophy of Science Association Meeting, Vancouver, Canadá, 2006.

53. Adúriz-Bravo, A.; Labarca, M.; Lombardi, O.; Em Avances en Didáctica de la Química: Modelos y Lenguajes; Merino, C.; Adúriz-Bravo, A.; Arellano, M., eds.; Pontificia Universidad Católica de Valparaíso: Valparaíso, 2013 (no prelo); Hoffmann, R.; 'keynote address to' the International Society for Philosophy of Chemistry 2009; Labarca, M.; Lastiri, M.; Em Epistemología e Historia de la Ciencia 2010; García, P.; Massolo, A., eds.; Universidad Nacional de Córdoba: Córdoba, 2010, pp. 308-314.

54. Scerri, E. R.; Nature Chem. 2009, 1, 679.

55. Bent, H.; New Ideas in Chemistry from Fresh Energy. AuthorHouse: Bloomington, 2006; Earley, J. E.; Found. Chem. 2009, 11, 65; Hendry, R. F.; Phil. Sci. 2006, 73, 864; Ruthenberg, K.; Found. Chem. 2009, 11, 79; Scerri, E. R.; Hyle 2005, 11, 127; Schwarz, W. H. E.; Found. Chem. 2007, 9, 139; Tolentino, M.; Rocha-Filho, R.C.; Chagas, A.P.; Quim. Nova 1997, 20,103. Vihalemm, R.; Found. Chem. 2010, 13, 97.

56. Um sítio da Internet mantido por Mark R. Leach contém centenas de imagens com representações diversas para o sistema periódico: http://goo.gl/MRZwa, acessada em Abril 2013.

57. Stewart, P.; Educ. Chem. 2005, 6, 165; Rich, R.; Laing, M.; Educ. Quím. 2011, 22, 162.

58. Janet, C.; Chem. News. 1929, 138, 372, 388; Sanderson, R.T.; J. Chem. Educ. 1964, 41, 187; Simmons, L.M.; J. Chem. Educ. 1948, 25, 658.

59. Katz, G.; The Chemical Educator 2001, 6, 324.

60. Dufour, F.; Em The Chemogenesis Web Book, Leach, M.R. (eds.), 1990. http://www.meta-synthesis.com/webbook.html, acessada em Abril 2013.

61. Stewart, P.; Edu. Chem. 2004, 41, 165.

62. Bent, H.; Weinhold, F.; J. Chem. Educ. 2007, 84, 1145.

63. Scerri, E. R.; J. Chem. Educ. 2008, 85, 585.

64. Scerri, E. R.; Found. Chem. 2010, 12, 69.

65. Schwarz, W. H. E.; J. Chem. Educ. 2010, 87, 444.

66. Laing, M.; Found. Chem. 2007, 9, 127; Sacks, L.; Found. Chem. 2006, 8,31 . 
67. Cronyn, N.W.; J. Chem. Educ. 2003, 80, 947.

68. Atkins, P.W.; Kaesz, H.; Chem. Int. 2003, 25, 14.

69. Rich, R.; J. Chem. Educ. 2005, 82, 1761.

70. Jensen, W. B.; J. Chem. Educ. 1982, 59, 634.

71. Clark, R; J. Chem. Educ. 2008, 85, 497; Lavelle, L.; J. Chem. Educ. 2008, $85,1482$.

72. Sneath, P.; Found. Chem. 2000, 2, 237; Restrepo, G.; Found. Chem. 2007, 9, 225.

73. Ostrovsky, V.; Found. Chem. 2005, 7, 235.

74. Bonchev, D.; Em The Mathematics of the Periodic Table; Rouvray, D. H.; King, R. B., eds.; Nova Science Publishers: New York, 2006, pp. 161-188.

75. Wang, S-G.; Schwarz, W.H.E.; Angew. Chem. Int. Ed. 2009, 48, 3404.

76. Scerri, E. R.; J. Sci. Educ. 2011, 12, 4.

77. Löwdin, P-O.; Int. J. Quan. Chem. Sym. 1969, 3, 331.

78. Friedrich, B.; Found. Chem. 2004, 6, 117.

79. Schwarz, W. H. E.; Rich, R.; J. Chem. Educ. 2010, 4, 435.

80. Eichler, M.L.; Educ. Quim. 2001, 12, 138; Mortimer, E.F.; Quím. Nova 1997, 20, 200; Schummer, J. (ed.); Hyle 1999, 5.2; Schummer, J. (ed.); Hyle 2000, 6.1 e 6.2; Trindle, C.; Croat. Chem. Acta 1984, 57, 1231.

81. Justi, R.; Gilbert, J.; Sci. Educ. 1999, 83, 163.

82. Erduran, S.; Sci. Educ. 2001, 10, 581.

83. Fischer, G.; Stud. Hist. Phil. Sci. 2006, 37, 562.

84. Earley, J.E.; J. Chem. Educ. 2001, 78, 455.

85. Francoeur, E.; Hyle 2000, 6 (1), 63.

86. Tomasi, J. ; Hyle 1999, 5 (2), 79.

87. Laszlo, P.; Hyle 2000, 6 (1), 85.

88. Zeidler, P.; Hyle 2000, 6 (1), 17.

89. Bhushan, N.; Rosenfeld, S.; J. Chem. Educ. 1995, 72, 578.

90. Hoffmann, R.; Laszlo, P. Angew. Chem. (English ed.) 1991, 30, 1.

91. Earley, J.E.; Annals N.Y. Acad. Sci. 2003, 988, xi.

92. Allin, S.B.; Hyle 2004, 10 (2), 179; Berger, D.; J. Chem. Educ. 2006, $83,995$.
93. Woody, A.; Annals N.Y. Acad. Sci. 2003, 988, 22.

94. Weisberg, M; Phil. Sci. 2004, 71, 1071.

95. Fischer, G.; Annals N.Y. Acad. Sci. 2003, 988, 16.

96. Hendry, R. F.; Phil. Sci. 2004, 71, 1048.

97. Brown, T.L.; Annals N.Y. Acad. Sci. 2003, 988, 209.

98. Goodwin, W.; Annals N.Y. Acad. Sci. 2003, 988, 141.

99. Stemwedel, J.; Phil. Sci. 2004, 71, 1060.

100. Stemwedel, J.; Annals N.Y. Acad. Sci. 2003, 988, 217.

101. Finatto, M.J.B.; Enzweiler, N.; Huang, C.; Eichler, M.L.; Del Pino, J.C.; Tradterm 2002, 8, 211; Finatto, M.J.B.; Eichler, M.L.; Del Pino, J.C.; Organon 2002, 16, 83. Finatto, M.J.B.; Del Pino, J.C.; Barbosa, R.G.; Corbellini, E.R.B.; Matraga 2006, 19, 85. Finatto, M.J.B.; Barbosa, R.G.; Del Pino, J.C.; Contrapontos 2006, 6, 263.

102. Harré, R.; Annals N.Y. Acad. Sci. 2003, 988, 1.

103. McNeill, K.L. \& Krajcik, J.; J. Res. Sci. Teach. 2008, 45, 53.

104. Talanquer, V.; Int. J. Sci. Educ. 2010, 32, 2393.

105. Talanquer, V.; Int. J. Sci. Educ. 2007, 29, 853.

106. Johnstone, A.; Chem Educ. Res. Pract. 2000, 1, 9.

107. Niaz, M.; Rodríguez, M.A.; Chem Educ. Res. Pract. 2001, 2, 159.

108. Scerri, E. R.; Chem Educ. Res. Pract. 2001, 2, 165.

109. Soares, I.M.F.; Bejarano, N.R.R.; Revista FACED (UFBA) 2009, 13, 01. Torres, A.; Bejarano, N.R.R.; Inv. Ens. Cienc. 2009, 14, 357; Bejarano, N.R.R.; Carvalho, A.M.P.; Cien. Educ. 2003, 9, 1.

110. Bulcão, M.; O Racionalismo da Ciência Contemporânea, Ed. UEL: Londrina, 1999.

111. Hoffmann, R.; O Mesmo e o Não-mesmo, Ed. Unesp: São Paulo, 2007.

112. Schummer, J.; Hyle 2001, 7.2; Schummer, J.; Hyle 2002, 8.1.

113. Afonso-Goldfarb, A.M.; Ferraz, M.H.M. Quim. Nova 1993, 16, 63.

114. Benjamin, C.; Dicionário de Biografias Científicas, Contraponto, São Paulo, 2007. Outras biografias são encontradas em: http://www.hyle.org/ journal/biographies.htm, acessada em Abril 2013. 